Received Date:

Revised Date:

Accepted Date:

Article Type: Original Article

Corresponding author mail id:thomashe@umflint.edu

-

\title{
Obesity in America: A Market Failure?
}

\section{By Thomas A. Hemphill}

Since the late 1980s, obesity in America has been a looming public health concern. In adults, obesity is defined as a condition where a person's body mass index (BMI) is of 30 kilograms/mass ${ }^{2}$ or above, while in children aged 2-19, obesity is where the child's BMI is at or above the $95^{\text {th }}$ percentile of the sex-specific BMI for age on the Centers for Disease Control's growth charts. Severe obesity for adults is where BMI is greater than 40, or they are more than 100 pounds over their ideal body weight or, for children, a triceps skin fold $>95^{\text {th }}$ percentile of all children. Recently, medical researchers found that, for the 2011-12 period, 35.3 percent of U.S. adults (aged 20 or older), 20.5 percent of teenagers (ages 12-19), 17.7 percent of children (ages 6-11), and 8.4 percent of young children (ages 2-5) have obesity, and 6.3 percent of U.S. adults having severe obesity. ${ }^{1}$ Among all major developed countries, the World Health Organization identified the United States (U.S.) has having the highest percentage of its population as obese, with New Zealand, Canada, and Australia following closely behind. ${ }^{2}$

Healthcare economists estimate that medical costs attributable to obesity in America increased to $\$ 147$ billion in 2008, up from $\$ 78.5$ billion in 1998 - or an 87.3 percent rise over a decade. ${ }^{3}$ Moreover, medical researchers forecast that by 2030, 42 percent of Americans will be obese and 11 percent will be severely obese. ${ }^{4}$ If these same Duke University and the Centers for Disease Control researchers' prediction holds true, obesity will cost the U.S. an extra \$550 billion in health-related expenses and a decline in workforce productivity. ${ }^{5}$ Other health care researchers estimate that, in 2013, severe obesity (in this case, defined as a person having a BMI This is the author manuscript accepted for publication and has undergone full peer review but has not been through the copyediting, typesetting, pagination and proofreading process, which may lead to differences between this version and the Version of Record. Please cite this article as doi: $\underline{10.1111 / \text { basr.12157 }}$

This article is protected by copyright. All rights reserved 
of 35 kilograms $/$ mass $^{2}$ ) cost the U.S. approximately $\$ 69$ billion, which accounted for 60 percent of the nation's total obesity-related expenses. ${ }^{6}$ Furthermore, these researchers identify approximately 11 percent of the cost of severe obesity being paid by Medicaid, 30 percent by Medicare and other federal health programs, 27 percent by private health plans, and 30 percent by out-of-private pocket. $^{7}$

In a recent working paper by Aneel Karnani, of the Ross School of Business, University of Michigan-Ann Arbor, Brian McFerran, of the Beedie School of Business, Simon Fraser University, and Anirban Mukhopadhyay, of the Hong Kong University of Science and Technology (hereafter Karnani et al.), these management scholars argue that obesity represents a market failure. ${ }^{8}$ In their research study, the authors start with the premise that the food and beverage industry is not operating an efficient market where people are making choices that are in society's best interest. The reasons supporting this premise are that consumers, especially children, are poorly informed about what causes weight gain ("medical research demonstrates that the central cause of obesity is caloric overconsumption, rather than the lack of exercise") or the long-term personal consequences of being obese. Moreover, a societal externality of obesity includes higher healthcare costs and reduced employee productivity.

\section{Obesity and Market Failure}

According to Karnani et al., the sub-field of public economics informs that government intervention is the institutional mechanism to address market failures. However, research in the strategic management literature suggests a range of corrective institutional actions, besides government regulation, to deal with market failures, including such private governance mechanisms as corporate social responsibility, industry self-regulation, and social activism (See Figure I below). In the marketplace, the authors argue that the effectiveness of any corrective mechanism depends critically on consumer behavior in response to an action. In their study, Karnani et al. evaluate the effectiveness of corporate social responsibility, industry selfregulation, social activism, and government regulation as to its effectiveness on consumer behavior and reducing obesity.

\section{Figure I}

\section{Obesity in America:}




\section{Corrective Institutional Mechanisms}
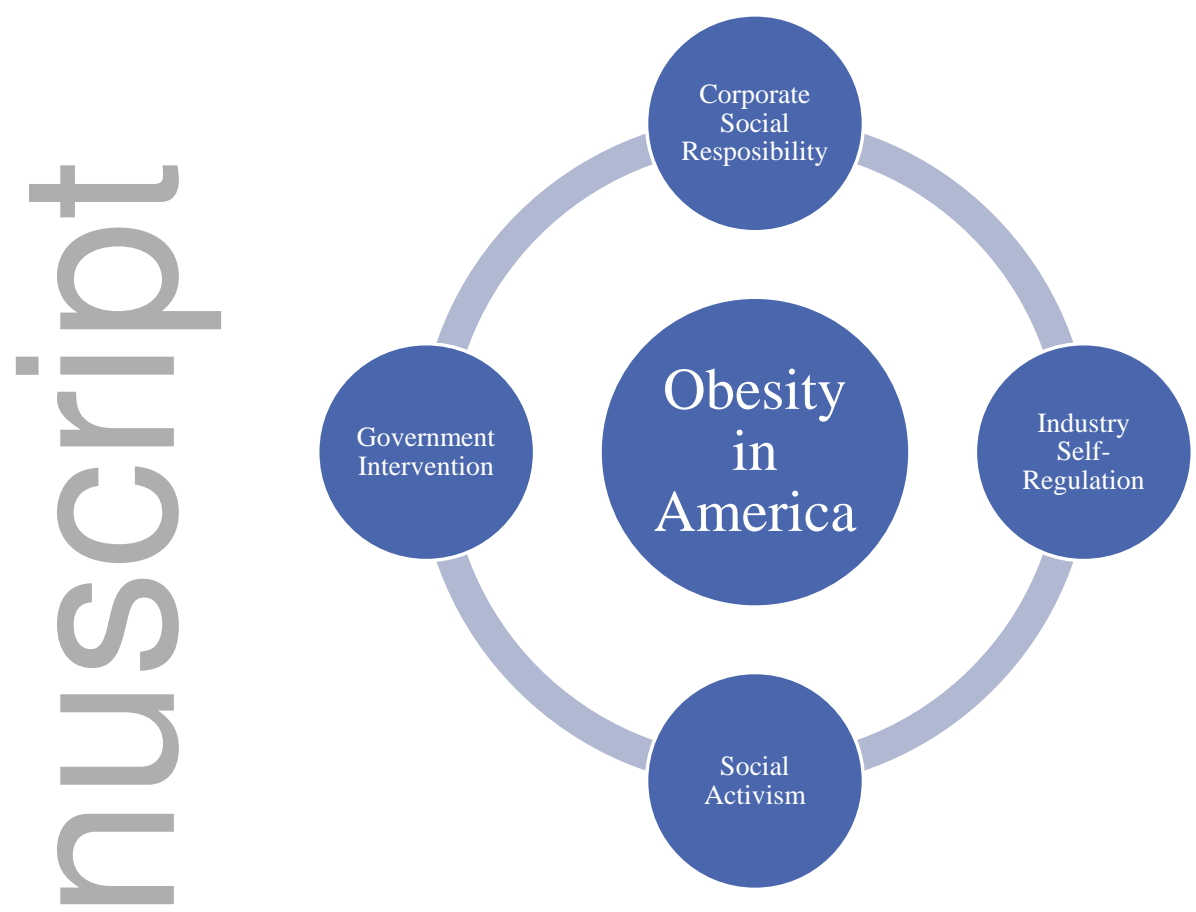

Corporate social responsibility. Karnani, et al. have found that food companies, instead of being part of the solution, actually exacerbate the obesity crisis. Food companies take an active role in deflecting accurate information about poor diet being the primary cause of obesity, and promote a message focused on exercise and a "balanced" lifestyle — a phenomenon the authors derisively termed "leanwashing". Empirical research shows that people who mistakenly underestimate the importance of bad diet are in fact more overweight than people who correctly believe that bad diet is the primary cause of obesity. This problem is further exacerbated because false information not only causes consumers to behave inappropriately to obesity, but false information disseminated today undermines confidence in the correct information when it is heard in the future. It is difficult for Karnani, et al. to understand how corporate social responsibility alone can play a positive, corrective role in the obesity crisis.

Industry self-regulation. The food industry has championed voluntary industry self-regulation and has supported several initiatives in response to concerns about marketing to children. Research reveals, however, that these initiatives have had modest impact and usually have not achieved societal objectives. An example of such a global initiative is the Responsible Advertising and Children (RAC) Programme, a self-regulatory body that represents advertisers, 
agencies and the media worldwide. Its Website proclaims that RAC is "acutely aware" of the issue of childhood obesity, and advocates a "holistic response to a multi-factorial problem." The Website goes on to state that studies reveal "lack of physical activity as the single most important cause of obesity... while illustrating how children's diets and their consumption of particular product categories (such as chocolate and soft drinks) are in no way linked to their Body Mass Index." Given such disregard for truth, science and medical research, Karnani et al. argue that it is impossible for RAC to help correct the market failure leading to obesity and further illustrates that self-regulation is ineffective given the conflicting interests of the food industry and society.

Social activism. The public health community has not succeeded in launching a large-scale civil movement to fight obesity. Unlike alcohol, drugs, or tobacco, the scope of the obesity problem is much larger, and anti-obesity activists cannot "demonize" overweight people as dangerous to society. While the best argument might be that obesity consumes enormous health care resources, this argument is too abstract and does not provoke the same sense of personal awareness or outrage among consumers on a large scale. For obesity, the message has to be 'make good choices, do this in moderation, set boundaries' - which is much more difficult to effectively convey. Smoking reduction succeeded only after a shift in emphasis to communitybased activism, holding cigarette manufacturers accountable and utilizing government intervention. Similarly, to fight obesity, civil society needs to prod the government to intervene.

\section{Government Intervention}

It is unlikely that market failure leading to obesity can be corrected via corporate social responsibility, industry self-regulation, or social activism; that leaves government intervention. There are three government interventions that policymakers can use to correct market failure: taxes/subsidies, market regulations, and education.

Tax/Subsidies. One tax/subsidies option would be raising the price (via taxation) of unhealthy foods; another would be to lower the price (via rebates or subsidies) of healthier alternatives, thus prices will reflect what is better for society, and consumers' demand functions will shift accordingly. Further, tax revenues can be directed to targeting the treatment of obesity, so more of the costs are borne by the purchaser. However, there is disagreement on what products or 
ingredients should be taxed; properly calibrating the size of the tax; and that such taxes are regressive, penalizing the poor (although such taxes might be particularly effective among the poor, as they are at greatest risk of obesity). A taxation alternative would be the alteration of agricultural policy and the subsidies of food that is high in calories (e.g., high fructose corn syrup, meat). Given the power of the agricultural lobby, and the fact that the public rarely blames these policies as a cause of obesity, the removal of the subsidies may be desirable but is highly unlikely. Another option might be to subsidize healthy food; however, there would likely be political resistance to consumers using "welfare" benefits to purchase healthier alternatives.

Market Regulation. There are three possible types of regulations that may serve to correct the market failures of obesity: restrictions on advertising, restrictions on distribution, and restrictions on the product itself. Food, especially fast food, is one of the most marketed categories. In 2012, fast food companies spent $\$ 4.6$ billion in advertising in the U.S., and children and teens were a major target. In addition to mainstream TV and print ads, companies invest heavily on the promotion of their products through event sponsorship, celebrity endorsements, branded product tie-ins, and social media. The central theme of food marketing is that "unhealthy eating (e.g., frequent snacking on calorie-dense and nutrient-poor food) is normal, fun, and socially rewarding." Advertisers clearly view promotion an important part of their business model, and studies do show these tactics have an effect on unhealthy food consumption. Likewise, government restrictions on advertising have a demonstrated effect on consumer demand.

A second class of regulation is restricting access to unhealthy food and/or increasing access to healthier alternatives. The central idea here - and supported scientifically - is that distribution drives consumption, and by making food more (or less) convenient (e.g., restricting snack food vending machines in schools), diets can be shaped. Stronger than merely restricting distribution is an outright ban on certain ingredients; for example, New York City and several municipalities in and around Boston have banned artificial trans-fats. However, the effects of the trans-fats ban on obesity and population health remain undocumented and it is unclear how the effects of an ingredient ban generalize to bans of entire product lines. There is good reason to believe that widespread bans of ingredients (and especially products) are unlikely, as they face stiff opposition from both industry (who fear for their profits) and consumers (who do not like being 
told what they cannot consume). Further, unless the ingredient is replaced with something that is both less harmful and lower in calories, it is not always clear how banning certain ingredients will result in less obesity. In addition, without geographically comprehensive legislation, there will remain free access to products outside of the ban area for many consumers.

A less coercive approach than formal bans on marketing actions are subtler "nudges" that can be employed to guide people to make better choices. Nudges preserve choice while also encouraging consumers to make choices that may correct market failures that can result from human biases. "Preserving choice" is an important element that serves as an alternative to more stringent regulations, which are often deemed anti-choice or "nanny state" policies. However, if nudges become legislated, how far from "shoves" are they? Matching the scale, scope, and fit of any possible treatment is challenging, and even renowned behavioral economists have noted that nudging is probably not the best way to solve the obesity crisis. ${ }^{9}$

Education. Education could potentially correct market failures by reducing the existing information gap in the marketplace between those who produce the food and those who consume it. Even free-market advocates can support education, since it preserves individual choice and increases the likelihood that an individual is making rational choices according to standard utility models. The empirical evidence on the effectiveness of education is mixed, as interventions that target actual behavior versus awareness, attitudes, or intentions have been shown to be more effective at changing consumption. Many interventions fail, however, because they insufficiently address consumer motivation, ability to take action, or environmental factors. For example, education is not going to help if one lacks access and financial ability to eat healthy. In conclusion, education, properly targeted, has been shown to have some effect, but education alone, without other structural changes, will certainly fail in addressing the obesity problem.

In conclusion, Karnani et al. argue that three of the four corrective mechanismscorporate social responsibility, consumer social activism, and industry self-regulation, all private governance-based-are unlikely to be effective on their own. Obesity is a difficult challenge that will require a multi-faceted solution involving all the four mechanisms to correct market failures, and especially government intervention. "We think reasonable government regulation is a possibility once we have a public discussion rooted in data and logic," says Aneel Karnani. ${ }^{10}$ 


\section{The Public Discussion Begins}

If one wants to seriously discuss long-term policy solutions to the obesity epidemic in America, the focus should be on targeting children, as children who are overweight or obese at 3 to 5 years old are five times more likely to be overweight or obese as adults. Medical researchers note that the prevalence of obesity in the United States is considered high, with one-third of adults and $17 \%$ of children obese, but it appears to have generally stabilized for the U.S. population between 2003-2004 and 2009-2010. ${ }^{11}$ A positive finding among this most recent data, however, is that there was a significant decrease in obesity among 2-5 year olds from 2004, when 13.9 percent were considered obese, to 2011-12, when 8.4 percent were considered obese - a 39.5 percent decrease in obesity in this critical age group. ${ }^{12}$

While there is no general consensus among public health care professionals and academics of why the decline in obesity among very young children is occurring, Barry M. Popkin, a researcher at the University of North Carolina at Chapel Hill, reports that families with children had been buying lower calorie foods over the past decade. ${ }^{13}$ Moreover, Popkin credits changes in the federally funded Special Supplemental Nutrition Program for Women, Infants and Children (WIC) for the decline in

obesity in very young children. ${ }^{14}$ The WIC program, which subsidizes food for low-income families, reduced funding for fruit juices, cheese and eggs, and increased funding for whole fruits and vegetables. ${ }^{15}$ Another causal explanation may be found is in the combination of federal, state and local policies, including the efforts by Michelle Obama to lead efforts to change young children's eating and exercise habits, as 10,000 child care centers nationwide have signed on to the First Lady's program. ${ }^{16}$

As mentioned earlier, Karnani et al. are advocates of "reasonable" government regulation to address the public health issue of obesity. However, what may be considered as reasonable government intervention, the researchers' fourth option, is also vulnerable to "nonmarket" failure and potential public health risk. For example, Dr. Aaron E. Carroll, professor of pediatrics, Indiana University, School of Medicine, notes that previous national Dietary Guidelines, issued jointly by the U.S. Department of Health and Human Services and the U.S. Department of Agriculture ... have recommended cutting down on meat, especially red meat, this meant that many people began to increase their consumption of carbohydrates. Decades later, it's not hard to 
find evidence that this might have been a bad move. Many now believe that excessive carbohydrates consumption may be contributing to the obesity and diabetes epidemics (italics add). ${ }^{17}$

Moreover, the market mechanism has been working over the past 30 years as it relates to American carbonated soft drink ("soda") consumption, as it is reported to be at the lowest level since $1985{ }^{18}$ Furthermore, U.S. soda volume dropped 1.2 percent in 2015 , the $11^{\text {th }}$ straight yearly decline, and annual per capita consumption of soda has dropped to 650 eight-ounce servings in 2015, as compared to 849 eight-ounce servings in 2000 - a 23.5 percent decline over the last 15 years. ${ }^{19}$ What is motivating this decline in soda consumption? American consumers are concerned over rising obesity and diabetes rates. These consumers are seeking other beverage alternatives to soda they deem healthier, such as cold-pressed juices and flavored or branded zero calorie bottled waters, that do not contain as many calories or artificial sweeteners, such as aspartame. ${ }^{20}$

Mintel, a Chicago-based market research firm, forecasts that the estimated $\$ 15$ billion bottled water industry (for 2015) will continue rising in sales volume at a rapid pace through 2020, with projected sales growth of 34.7 percent for this industry category. ${ }^{21}$ In a recent Mintel survey of U.S. bottled water consumers, 48 percent of respondents report they are drinking more flavored bottled waters to replace high sugar drinks. ${ }^{22}$ Tax initiatives focused on soda and other sugar-added beverages are underway, however, at the municipal-level in a number of cities across America. For example, Oakland city council recently voted to place a penny-per-ounce tax on its 2016 ballot. In San Francisco and Boulder, local residents have been collecting signatures for a similar initiative to the enacted Oakland tax assessment. ${ }^{23}$

However, considering the growing evidence of the continuing decline in the consumption of soda over the last 15 years, the information-based strategy being considered by the Baltimore City Council, requiring store signs warning that sugary drinks contribute to obesity, diabetes and tooth decay, is a less draconian (and regressive from a taxation perspective) response to this public health issue. $^{24}$ In July 2016, San Francisco will begin enforcing a warning similar to what is being considered in Baltimore on billboards and other public advertisements. ${ }^{25}$ Moreover, the soft drink industry is also responding to consumer demands, as it is innovating with smaller packaging sizes and lower-calorie drinks. ${ }^{26}$ 
Will this obesity epidemic in America continue to stabilize or decline over time? New data collected on obesity in America should provide evidence of whether the nation has turned the corner on the obesity epidemic, especially if the positive trend found in the 2-5 year age group continues in the 6-11 age group. If the most recent data collected on obesity among Americans continues to mirror the trend found in the 2011-12 data, the evidence for what mix of institutional activities results in reduced obesity - whether found in corporate social responsibility, industry self-regulation, social activism, or government intervention - will provide the direction needed to continue this public health trend away from America's epidemic levels of obesity and severe obesity.

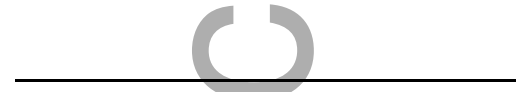

(

${ }^{1}$ Ogden, Cynthia L., Carroll, Margaret D., Kit, Brian K., and Flegal, Katherine M. "Prevalence of Childhood and Adult Obesity in the United States, 2011-12", Journal of the American Medical Association, Vol. 311, No. 8, 2014, 806-814.

2 (No Author), "Focus on Obesity: Global Obesity”, Health Affairs, Vol. 34, No. 11, 2015, 18081809.

${ }^{3}$ Finkelstein, Eric A., Trogdon, Justin A., Cohen, Joel W., and Dietz, William H., "Annual Medical Spending Attributable to Obesity: Payer-and-Service-Specific Estimates", Health Affairs, Vol. 28, No. 5, 2009, 822-831.

${ }^{4}$ Finkelstein, Eric A., Khavjou, Olga A., Thompson, Hope, Trogdon. Sherry, Betty Lou, and Dietz, William H., "Obesity and Severe Obesity Forecasts Through 2013”, American Journal of Preventative Medicine, Vol. 42, No. 2, 2012, 563-570.

${ }^{5}$ Ibid.

${ }^{6}$ Wang, Y. Claire, Pamplin, John, Long, Michael W., Ward, Zachary J., Gortmaker, Steven L., and Andreyva, Tatianna, "Severe Obesity In Adults Cost State Medicaid Programs Nearly \$8 Billion in 2013", Health Affairs, Vol. 34, No. 11, 2015, 1923-1931.

${ }^{7}$ Ibid.

${ }^{8}$ Karnarni, Aneel, McFerran, Brian, and Mukhopadhyay, Anirban. "Correcting the Market Failures to Address the Obesity Crisis", Working Paper, Ross School of Business, University of Michigan-Ann Arbor, May 2015.

${ }^{9}$ Marlow, Michael L. and Abdukadirov, Sherzod. "Can Behavioral Economics Combat Obesity?", Regulation: The Cato Review of Business and Government, Vol. 35, No. 2, 2012, 1418.

This article is protected by copyright. All rights reserved 
${ }^{10}$ (No Author), "Combating Obesity as a Market Failure", August 28, 2015, www.http:// michiganross.umich.edu/rtia-articles/combating-obesity-market-failure.

${ }^{11}$ Op cit., Ogden, Cynthia L, et al., Note 1.

${ }^{12}$ Ibid.

${ }^{13}$ Tavernis, Sabrina, "Obesity Rate for Young Children Plummets $43 \%$ in a Decade", The New York Times, February 25, 2014, www.nytimes.com/2014/02/26/health/obesity-rate-for-youngchildren-plummets-43-in-a-decade.ktm?_r=0, accessed on May 22, 2016.

14 Ibid.

${ }^{15}$ Ibid.

16 Ibid.

${ }^{17}$ Carroll, Aaron, E., "Behind New Dietary Guidelines, Better Science”, The New York Times, February 23, 2014, www.nytimes.com/2015/02/24/upshot/behind-new-dietary-guidelines-betterscience.html, accessed May 22, 2016.

${ }^{18}$ Kell, John, "Soda Consumption Falls to 30-Year Low in the U.S.”, March 29, 2016, Fortune, www.http.//fortune.com/2016/03/29/soda-sales-drop-11th-year/, accessed May 22, 2016.

${ }^{19}$ Esterel, Mike, "Big Soda Faces Test in Philadelphia", The Wall Street Journal, May 20, 2016, B1-2.

${ }^{20}$ Op cit., Kell, Note 18.

21 (No Author), “U.S. Bottled Water Market Grows 6.4 Percent in 2015”. Beverage Industry, February 26, 2016, http://www.bevindustry.com/articles/89123-us-bottled-water-market-grows64-percent-in-2015, accessed May 22, 2016.

${ }^{22}$ Ibid.

${ }^{23}$ Op cit., Esterel, Note 19.

24 Ibid.

25 Ibid.

${ }^{26}$ Ibid. 